\title{
Study on the Difference of Photochemical Efficiency of Sunlight Photocatalyst in Degradations Dye Aqueous RhB Solution in Different Seasons
}

\author{
Hong Kai Jheng ${ }^{\mathrm{a}^{*}}$, Po Jen Tseng ${ }^{\mathrm{a}}$, Chang Zhang Zeng ${ }^{\mathrm{a}}$, Chao Yin Kuo ${ }^{\mathrm{a}}$ \\ ${ }^{a}$ Department of Safety Health and Environmental Engineering, National Yunlin University of Science and Technology, Yunlin, Taiwan
}

\begin{abstract}
The purpose of this study is to modify $\mathrm{TiO}_{2}$ with bismuth oxide $\left(\mathrm{Bi}_{2} \mathrm{O}_{3}\right)$ and potassium hydrogen iodate $\left.\left(\mathrm{KH}_{(} \mathrm{IO}_{3}\right)_{2}\right)$ to research the effect of $\mathrm{RhB}$ degradation in natural sunlight within different seasons. The catalyst was made by fixing the mole $\%$ of $\mathrm{I} / \mathrm{Bi}_{2} \mathrm{O}_{3} / \mathrm{TiO}_{2}$ to $2: 1: 1,10 \mathrm{mg} / \mathrm{L}$ of $\mathrm{RhB}$ was the target pollutant, and compare the difference of $\mathrm{I} / \mathrm{Bi}_{2} \mathrm{O}_{3} / \mathrm{TiO}_{2}$ modified catalysts in natural sunlight within different seasons. According to the XRD crystal phase identification, it can be seen that the characteristic peaks of the modified photocatalysts are consistent with the structures of anatase and rutile, had not be offset. At the same time, there aren't other impurity crystal phases were found, and the photocatalysts is still retains the basic type, which means we successfully prepared the $\mathrm{I} / \mathrm{Bi}_{2} \mathrm{O}_{3} / \mathrm{TiO}_{2}$ composite photocatalysts. The result of UV-visible analysis showed that the composite photocatalysts had the phenomenon of red-shift, and there was a second absorption wavelength in the range of visible light. That is, the energy gap will be reduced and the utilization under visible light will be increased by the addition of iodine and bismuth oxide. The pure $\mathrm{TiO}_{2}$ has no the phenomenon above. In this study, the photodegradation efficiency in 60 minutes of photocatalysts experiments under the actual solar light at summer and winter were $58.9 \%$ and $44.4 \%$ respectively. The photocatalysts still retained a good removal efficiency after five repeat photocatalytic. In other words, the photocatalyst has the characteristics of excellent durability.
\end{abstract}

\section{Background}

Rhodamine B (RhB) is a kind of typical industrial dye, mainly used in textile, plastic, leather, dyeing, papermaking and printing industries. After dyeing and finishing, the waste water contained the dye were directly discharged to nearby water bodies which would lead to serious environmental pollution. According to the study, 700,000 tons of dyes are produced annually in the world, and about $10 \%$ to $15 \%$ of the dye were lost from the fibers and got into the wastewater during the process of dyeing and finishing [1]. If Synthetic dyes which are untreated to the water was penetrated into groundwater and surface water would block sunlight, reduce the amount of plankton in the water and affect the aquatic diversity [2].

There are many literatures currently studying the removal of pollutants rhodamine $B$, such as photocatalysis [3-5], chemical oxidation [6], filtration, biological treatment, ozone, adsorption method [7-8], electrochemical method [9] and other methods.

In view of RhB harmful for healthy, such like eyes and skin, redness and carcinogenic [10]. May be harmful to human health, Taiwan's Ministry of Health and Welfare announced RhB as one of the toxic substances management projects in 2017. It was widely used in industrial products and many contributions to human life.
However, due to its toxicity and potential, lead to more and more problems impact human health. For the reason above, RhB was set as a target pollutant to find out the degradation capacity of photocatalysts in this study.

The titanium dioxide energy gap is $3.2 \mathrm{eV}$, most of which can be used in the ultraviolet range. By adding different concentrations of iodine and bismuth elements, the photocatalyst absorption wavelength can be red shifted to the visible light region, and the photocatalytic activity in the visible light range can be increased [11]

Therefore, this study used iodine and bismuth oxide to modify the titanium dioxide catalyst, expect to increase the visible light absorption rate and photocatalytic activity of the catalyst, and to investigate the degradation capacity of RhB.

\section{Methods}

\subsection{Photocatalytic Reaction}

Fig 1 presents that under sunlight irradiation, the photogenerated electrons of the $\mathrm{TiO}_{2}$ conduction band (CB) will transfer to the $\mathrm{CB}$ of $\mathrm{Bi}_{2} \mathrm{O}_{3}$; due to the holes transfer in the opposite direction from the electrons, the photogenerated holes of the $\mathrm{Bi}_{2} \mathrm{O}_{3}$ from valence band (VB) move to the $\mathrm{VB}$ of $\mathrm{TiO}_{2}$, which charge separates

\footnotetext{
* Corresponding author: nike05270601@gmail.com
} 
[12], this process is called interparticle electron transfer (IPET); the oxygen from air will be reduce back to superoxide radicals $\left(\bullet \mathrm{O}_{2-}\right)$ by accepting electrons on $\mathrm{CB}$; the hydroxyl radicals $(\bullet \mathrm{OH})$ produced by $\mathrm{H}_{2} \mathrm{O}$ reacting with the holes on VB [13], Then radical formed at the surface quickly undergoes degradation reaction. $\mathrm{I}^{7+}, \mathrm{I}^{5+}$ and $\mathrm{I}^{-}$were produced with adding $\mathrm{IO}^{3-}$ that act as electron acceptors, to inhibit electron-hole pairs recombination and promoting the separation of photogenerated, enhancing photocatalytic activity [14].

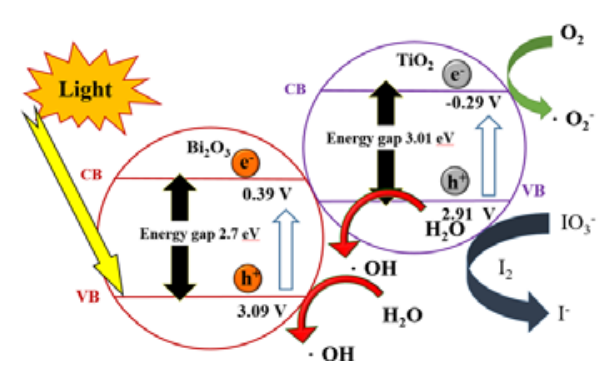

Fig 1. Proposed mechanism for RhB degradation by I/ $\mathrm{Bi}_{2} \mathrm{O}_{3} / \mathrm{TiO}_{2}$ under simulated solar light irradiation

\section{$2.2 \mathrm{l} / \mathrm{B} \quad \mathrm{i}_{2} \mathrm{O}_{3} / \mathrm{TiO}_{2} \quad$ Composite Photocatalysts Preparation}

In this study, the catalyst was made by fixing the mole\% of $\mathrm{I} / \mathrm{Bi}_{2} \mathrm{O}_{3} / \mathrm{TiO}_{2}$ to 2: 1: 1 . Potassium hydrogen iodate and bismuth oxide were mixed and then doped into titanium dioxide to prepare a suspension. The surface of a smooth glass piece was ground with sandpaper, and then the glass piece was etched in 5M molar concentration sodium hydroxide aqueous solution. After cleaned and dried in a natural environment, continually dried at $105{ }^{\circ} \mathrm{C}$ for 1 hour. The suspension would be coated onto glass slides. After the modify process, completing the preparation of $\mathrm{I} / \mathrm{Bi}_{2} \mathrm{O}_{3} / \mathrm{TiO}_{2}$ fixed photocatalysts which were named as 2.0IBT.

\subsection{Photocatalytic Reaction Device}

The photocatalytic reaction device used in this study is shown in Fig 2. Preparation of $10 \mathrm{mg} / \mathrm{L} \mathrm{RhB}$ aqueous solution as target contaminant, and $250 \mathrm{~mL}$ of the $\mathrm{RhB}$ solution was added to the reaction vessel and then add the photocatalyst. The sample was taken to measure by syringe every 10 minutes by spectrophotometry.
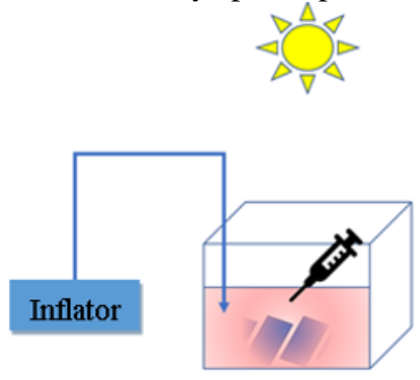

Fig 2. Photocatalytic Reaction Device

\section{4 photocatalysts experiments}

The experiment under natural light was divided into sunlight photocatalysis experiment under different seasons and experiments of repeated durability. Explore the photocatalytic effect and recycling efficiency of the catalyst under natural light different intensities.

\section{Results}

\section{1 physical analysis}

The $\mathrm{I} / \mathrm{Bi}_{2} \mathrm{O}_{3} / \mathrm{TiO}_{2}$ composite photocatalyst prepared in this study forms an anatase with higher activity. The Xray powder diffraction apparatus (XRD) analyses the signal and compares the data of the JCPDS(Joint Committee on the Powder Diffraction Standards) database. The anatase crystal phase is the standard map JCPDS No. 21-1272 shows that the diffraction peak position is $2 \theta=25.3^{\circ}(101), 37.8^{\circ}(200), 54.11^{\circ}(105)$, $54.8^{\circ}(211)$ and $62.4^{\circ}(204)$, the rutile crystal phase in the standard map JCPDS, the diffraction peak position is 2 $\theta=27.2^{\circ}(110), 35.4^{\circ}(101), 38.3^{\circ}(200), 40.4^{\circ}(111)$, $43.2^{\circ}(210), 53.3211(211), \quad 55.7^{\circ}(220), 64.3^{\circ}(310)$, $68.4^{\circ}(301)$, and $68.5^{\circ}(112)$, and the anatase and rutile crystals know each other as long as the peaks are $2 \theta=$ $25.5^{\circ}, 2 \theta=27.5^{\circ}$. From Fig 3, it can be observed that the $\mathrm{I} / \mathrm{Bi}_{2} \mathrm{O}_{3} / \mathrm{TiO}_{2}$ composite photocatalyst has both an anatase and a rutile crystal phase that belong to a photocatalyst of a bimorph phase structure.

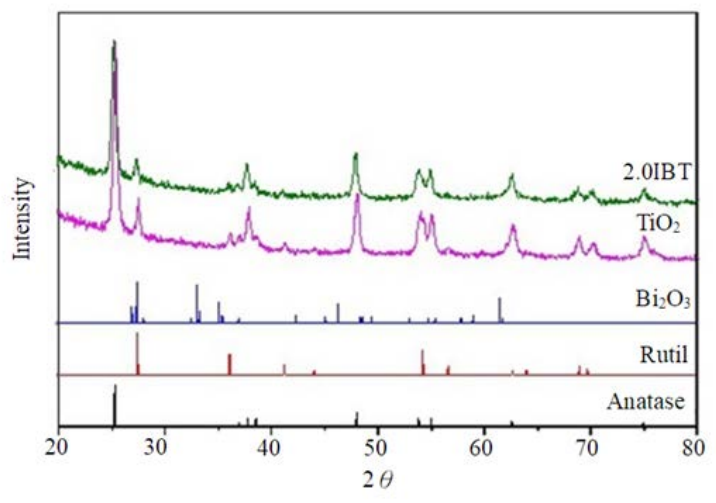

Fig 3. XRD patterns of $\mathrm{I} / \mathrm{Bi}_{2} \mathrm{O}_{3} / \mathrm{TiO}_{2}$ photocatalyst

The surface of the catalyst was magnified 30,000 times with a scanning electron microscope (SEM) to observe the condition of the catalyst surface. In order to meet the SEM analysis requirements, the catalyst was grounded into a powder for surface image photographing. From the Fig 4, we could observe that the surface was irregularly granular and stacked, which was a nanoscale structure. 

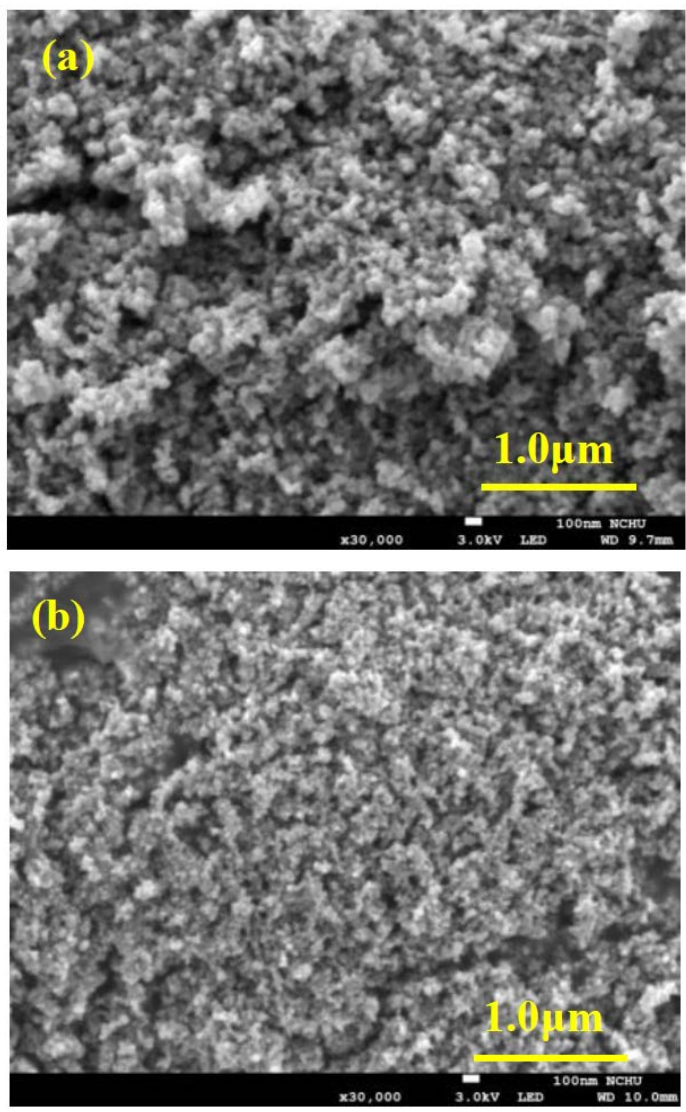

Fig 4. SEM images (a) $\mathrm{TiO}_{2}$ (b) 2.0IBT

In Table 1 , the absorption wavelengths are $\mathrm{TiO}_{2}(411$ $\mathrm{nm}$ ) and 2.0 IBT (414 nm, $502 \mathrm{~nm}$ ), respectively. The catalyst gap can be obtained by conversion to the formula. The energy gaps are $\mathrm{TiO}_{2}(3.02 \mathrm{eV})$ and 2.0 IBT (3.01 eV, $2.47 \mathrm{eV}$ ), respectively. After adding iodine and bismuth, the titanium dioxide catalyst can be modified to generate an absorption wavelength to visible light. The phenomenon of regional movement produces a phenomenon of red shift, which can increase the utility of the light source and increase the photocatalytic activity of the catalyst.

Table 1. The absorption wavelength and the energy gap calculation of various photocatalyst

\begin{tabular}{ccc}
\hline samples & $\begin{array}{c}\text { absorption } \\
\text { wavelength }(\mathrm{nm})\end{array}$ & $\begin{array}{c}\text { band gap } \\
\text { energy }(\mathrm{eV})\end{array}$ \\
\hline $\mathrm{TiO}_{2}$ & 411 & 3.02 \\
$2.0 \mathrm{IBT}$ & 414,502 & $3.01,2.47$ \\
\hline
\end{tabular}

\subsection{Photocatalytic reaction}

In this study, 2.0 mol percent $\mathrm{I} / \mathrm{Bi}_{2} \mathrm{O}_{3} / \mathrm{TiO}_{2}$ composite catalyst (2.0 IBT) was prepared, and photocatalytic experiments were performed with the actual sunlight of summer and winter. The results showed that the photodegradation efficiency between summer and winter was $58.9 \%$ and $44.4 \%$ after 60 minutes respectively.

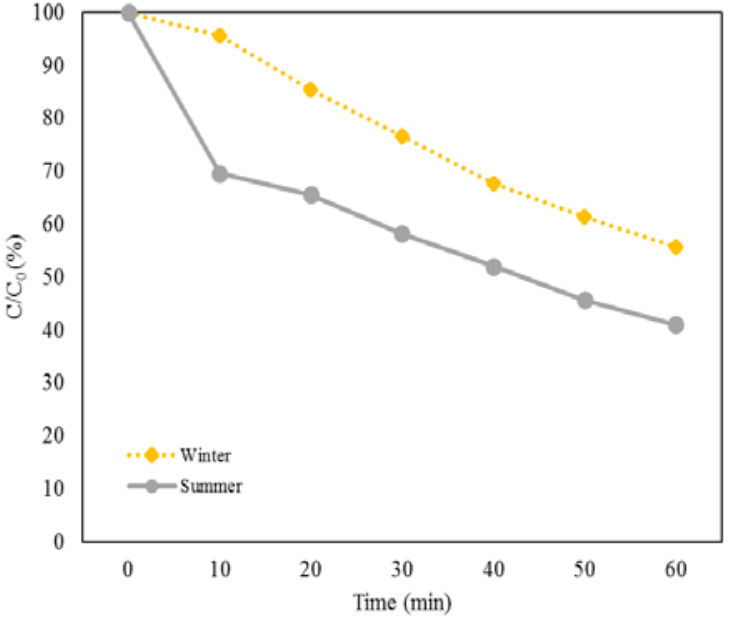

Fig 5. RhB degradation of photocatalysts respectively, under winter and summer sun light $(\mathrm{RhB}=10 \mathrm{mg} / \mathrm{L} ; \mathrm{pH}=4.03 ; \mathrm{t}=60 \mathrm{~min}$; Winter light intensity $=750 \sim 1171 \mathrm{watt} / \mathrm{m}^{2}$ : Summer light intensity $=900 \sim 1214$ watt $/ \mathrm{m}^{2}$ )

The 2.0 IBT of this experiment was subjected to photocatalytic experiments in the actual sunlight, and the change of photodegradation efficiency in the absence of catalyst replacement was investigated. Fig 6 . shows the five-repetition photocatalytic RhB concentration equilibrium diagram of 2.0 IBT catalyst under actual sunlight irradiation. Through five repeated durability experiments, it can be observed that after five photocatalytic experiments under actual sunlight, it can still maintain good removal efficiency under sun light. Shows that the fixed photocatalyst prepared in this study had good reusability.

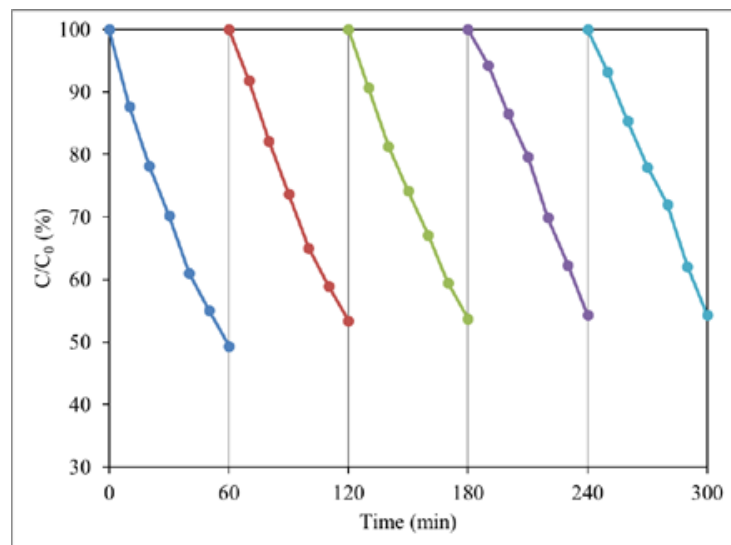

Fig 6. Durable tests for degradation of aqueous RhB using photocatalysts

$(\mathrm{RhB}=10 \mathrm{mg} / \mathrm{L} ; \mathrm{pH}=4.03 ; \mathrm{t}=300 \mathrm{~min}$ :

light intensity $=750 \sim 1171$ watt $/ \mathrm{m}^{2}$ )

\section{Conclusion}

In this study, $\mathrm{RhB}$ was the target pollutant, that was compared the difference of $\mathrm{I} / \mathrm{Bi}_{2} \mathrm{O}_{3} / \mathrm{TiO}_{2}$ modified catalysts in natural sunlight within different seasons. 
According to the XRD and UV-visible appraisal, the photocatalysts were still retained the basic type and energy gap could be reduced by the addition of iodine and bismuth oxide. It was displayed we successfully prepared the $\mathrm{I} / \mathrm{Bi}_{2} \mathrm{O}_{3} / \mathrm{TiO}_{2}$ composite photocatalysts the utilization under visible light will be increased.

In this photocatalytic reaction, the photodegradation efficiency in 60 minutes of photocatalysts experiments under the actual solar light at summer and winter were $58.9 \%$ and $44.4 \%$ respectively. The photocatalysts were still retained good removal efficiency after five repeats photocatalytic. Confirms that the photocatalysts prepared in this research were excellent reusability.

\section{References}

1. Singh. P, Mondal. K, Sharma. A., Reusable electrospun mesoporous $\mathrm{ZnO}$ nanofiber mats for photocatalytic degradation of polycyclic aromatic hydrocarbon dyes in wastewater. J. Colloid Interface Sci, 394, 208-215 (2013)

2. Anirudhan. T. S, Ramachandran. M., Adsorptive removal of basic dyes from aqueous solutions by surfactant modified bentonite clay (organoclay): kinetic and competitive adsorption isotherm. Process Saf Environ, 95, 215-225. (2015)

3. Shabat-Hadas. E, Mamane. H, Gitis. V., Rhodamine $B$ in dissolved and nano-bound forms: Indicators for light-based advanced oxidation processes. Chemosphere, 184, 1020-1027 (2017)

4. Alvi. M. A, Al-Ghamdi. A. A., Synthesis of $\mathrm{ZnO}$ nanostructures via low temperature solution process for photocatalytic degradation of rhodamine $B$ dye. Mater. Lett, 204, 12-15 (2017)

5. Seo. H. K, Shin. H. S., Study on photocatalytic activity of $\mathrm{ZnO}$ nanodisks for the degradation of Rhodamine B dye. Mater. Lett, 159, 265-268 (2015)

6. Shabat-Hadas. E, Mamane. H, Gitis. V., Rhodamine $B$ in dissolved and nano-bound forms: Indicators for light-based advanced oxidation processes. Chemosphere, 184, 1020-1027 (2017)

7. Vasu. A. E., Studies on the removal of Rhodamine $B$ and malachite green from aqueous solutions by activated carbon. J. Chem, 5(4), 844-852 (2008)

8. Hayeeye. F, Sattar. M, Chinpa. W, Sirichote. O., Kinetics and thermodynamics of Rhodamine $B$ adsorption by gelatin/activated carbon composite beads. Colloids Surf. A Physicochem. Eng. Asp, 513, 259-266 (2017)

9. Jinisha. R, Gandhimathi. R, Ramesh. S. T, Nidheesh. P. V, Velmathi. S., Removal of rhodamine B dye from aqueous solution by electro-Fenton process using iron-doped mesoporous silica as a heterogeneous catalyst. Chemosphere, 200, 446-454 (2018)

10. Cheng. Z. L, Li. Y. X, Liu. Z. Fabrication of graphene oxide/silicalite-1 composites with hierarchical porous structure and investigation on their adsorption performance for rhodamine B. J Ind Eng Chem, 55, 234-243(2017).

11. Henderson. M. A., A surface science perspective on $\mathrm{TiO}_{2}$ photocatalysis. Surf. Sci. Rep, 66(6-7), 185297 (2011)

12. Ren. C, Qiu. W, Zhang. H, He. Z, Chen. Y., Degradation of benzene on $\mathrm{TiO}_{2} / \mathrm{SiO}_{2} / \mathrm{Bi}_{2} \mathrm{O}_{3}$ photocatalysts under UV and visible light. J. Mol. Catal. A: Chem, 398, 215-222 (2015)

13. Kuo. C.Y, Li. T.H, Syu. S.E., Preparation of $\mathrm{Bi}_{2} \mathrm{O}_{3} / \mathrm{TiO}_{2}$ fixed photocatalysts and degradation of aqueous Bisphenol A under simulated sunlight, paper presented. Material and Environmental Sciences (ACCMES), Japan (2016)

14. Kuo. C.Y, Hsiao. H.M., Preparation of iodine doped titanium dioxide to photodegrade aqueous bisphenol A under visible light. Process Saf Environ. 95, 265-270 (2015) 